\title{
Unintended consequences as evidence to mission distortion: Reconsidering the intended contributions of policing to the public health
}

\author{
James Clover*
}

This article is related directly to the recent Law Enforcement Public Health (LEPH) Conference in Toronto, Canada, October 2018

For years I have encouraged my students to explore the unintended consequences of both policy and the subsequent operations within the criminal justice system, in a measure to aid their development in critical thinking and leverage their bright minds to seek creative resolutions to the issues we both face and create in policing.

During my participation at the 2018 Law Enforcement and Public Health Conference in Toronto (LEPH2018), I experienced a renewed confirmation that the unintended consequences of policing may be the evidence required to justify the re-examination of what the expected outcomes from policing responses are, as they relate to the mission of securing the public health.

The fourth iteration of this international conference, convened by the Centre for Law Enforcement \& Public Health and supported by the Journal of CSWB, brought together practitioners, academics, and government from a variety of sectors to explore the intersect that exists between policing and public health. This gathering introduced a breadth of themes, topics, and assignments ranging from the influence of health determinants in criminal behaviour, the emerging field of Epidemiological Criminology, and the economics of illness and corrections. It also included the formation of a special interest group to develop a multisector-influenced curriculum for police officers relating to positive community health outcomes.

I was responsible for the facilitation of a panel presentation on how policing efforts may, as politely captured by conference organizers, ameliorate or exacerbate the risk to public health in marginalized communities. The panel was composed of people and professions from across the globe, and it is here where I met a young police officer from West Africa. Looking smartly dressed in his grey police uniform, clearly nervous about his pending contribution, this young man had travelled many miles to share his experience with a collection of professionals from around the world.
He quietly described his role as the HIV/AIDS Prevention Officer, and highlighted the topic of sex work in his jurisdiction. The sale of sexual services in his country is illegal, and police officers are trained to look for indicia of sex workers as part of their duty to conduct sanctioned work, to enforce the law, and to obtain convictions in court. As the panelist explained, police officers are trained to look for short dresses, exposed breasts, and the possession of condoms.

Having previously been the team commander for a police unit dedicated to investigating sex exploitation through collaboration with sex workers, I was keenly aware of where this conversation was heading. Independent of the reasons why men and women sell their sexuality for money, it could easily be anticipated that the sex workers described in this presentation would respond in their own manner to police protocols relating to the indicia of sex work. In an effort to avoid detection by police, sex workers would dress more common, ensure their bodies were covered, and would be less likely to use or possess condoms during their interaction with sex consumers.

The young police officer had no need to articulate the policy conflict that was revealed. With only eight years in his profession, this police officer had exposed the unintended consequence of police training relating to the practices of enforcement of sexual service laws in that countryoutcomes that run in direct conflict with the mission to address the issue of systemic disease transmission within a vulnerable population.

For the remainder of the conference, in other presentations I was privileged to attend, I leveraged this story of police training and disease control during my interaction with conference delegates. How does the traditional role that police organizations assume, and the actions those organizations take to fulfill that mandate, conflict or misalign with the mission of addressing overall community health?

Models of modern policing over the past 20 years have been branded with strategies and approaches such as

\footnotetext{
Correspondence to: James Clover, Department of Public Safety and Justice Studies, MacEwan University, Faculty of Health and Community Studies, City Centre Campus, c/o PO Box 1796, Edmonton, AB T5J 2P2, Canada.

E-mail: cloverj@macewan.ca
} 
"community-based policing", "intelligence-led policing", and, most recently, "evidence-led policing". Our current climate now includes the aggressive professionalization of the police tradecraft through additional training demands and increased academic standards, as observed in industry movements such as the Police Education Qualifications Framework championed by the College of Policing in England and Wales, among others.

These models of policing cannot be held solely responsible for the distortion that exists between the mission of law enforcement and that of public health, but I propose these models will continue to contribute to the conflict until we reconsider the expected or intended outcomes of police work as it relates to the overarching approach to improving the health of our communities.

If we choose to create a hierarchy to the shared social responses required to meet the needs of the community, and elevate the mission of public health as the overarching umbrella that guides all, we will likely confirm that a healthy community is a safe community. And if the ultimate measure of police work can be evaluated through the filter of public health, and not only through the historic lens of combating the evident symptoms of an unhealthy environment as presented by crime and disorder, we might minimize those instances where the good work of police runs counter to collective efforts in securing public health and safety for all.

\section{CONFLICT OF INTEREST DISCLOSURES}

The author declares there are no conflicts of interest, and this submission does not necessarily reflect the opinions of the author's affiliations.

\section{AUTHOR AFFILIATIONS}

*Edmonton Police Service, Edmonton, and Department of Public Safety and Justice Studies, MacEwan University, Faculty of Health and Community Studies, Edmonton, AB, Canada. 